\title{
Stimulus selection and the redundant-trigram model of paired-associa te learning
}

\author{
FRANKLIN M. BERRY \\ Columbus College, Columbus, Ga. 31907 \\ EDWARD M. DUNCAN \\ University of Georgia. Athens. Ga. 30601 \\ and \\ STEVEN R. COLE \\ University of California at Los Angeles \\ Los Angeles. Calif. 90024
}

College Ss acquired paired associates (PAs) consisting of redundant trigrams (trigrams with no repeated letters) paired with single-digit responses, whereupon they were tested for single-letter selection and quizzed as to how they had learned each PA. The purpose of the study was to determine whether or not college Ss process redundant trigrams on the basis of their initial characteristics to any significant extent. The results showed that a significant number of the trigrams were indeed processed on the basis of the initials they spelled out. It was argued that the occurrence of initial selection makes the redundant-trigram model a less useful research model than was heretofore supposed.

Since A. R. Mattocks (cited in Underwood \& Schulz, 1960) observed that college students often select only the first letter of nonsense trigrams for use as their effective stimuli in paired-associate (PA) learning, the "redundant-trigram" model of PA learning has enjoyed great popularity in investigations of the process of stimulus selection (e.g., for adult Ss, Berry, Detterman, \& Mulhern, 1973; Davis, Brown, \& Ritchie, 1968; Lovelace \& Blass, 1968; Lovelace \& Greenberg, 1969; Postman \& Greenbloom, 1967; Rabinowitz \& Witte, 1967: Richardson, 1972, and for child and/or retarded Ss, Baumeister \& Berry, 1970; Berry \& Baumeister, 1973; Berry, Joubert, \& Baumeister, 1971, 1972; Rabinowitz \& McClinton, 1971). It is possible, however, that the redundant-trigram research model is not as useful as an analogous model based on triads of unrelated words. This latter model has been used only infrequently in studies of stimulus selection (Horowitz, Lippman, Norman, \& McConkie, 1964; Wichawut \& Martin, 1970).

In the sole investigation in which the redundant trigram and its "redundant-word-triad" analogue have been compared directly (Berry \& Cole, 1973), only one difference was found in the manner in which college Ss processed these different types of triads: the word-triad model yielded higher $(\mathrm{p}<.10)$ estimates of cue selection consistency (see Richardson, 1971) than did the redundant-trigram model. Berry and Cole suggested that the basis for the lowered consistency scores could be that trigram stimuli "... are likely to spell out all or parts of initials with special meaning to some of the Ss [p. 403]."

The present experiment was designed to follow up Berry \& Cole's (1973) conjecture that college Ss are likely to process redundant trigrams on the basis of their initial characteristics. The aısswer to this question seemed important because such "initial processing" would be likely to obscure other less idiosyniratic processing strategies. Ironically, the question of initial selection could be approached most directly by use of the postexperimental questionnaire technique used in the first letter-selection experiment reported by Mattocks (see Underwood \& Schulz, 1960). That is. after the list of redundant trigram:digit PAs had been acquired, Ss were tested for single-letter selection and they were asked to indicate how they had learned each PA.

\section{METHOD \\ Subjects}

The Ss were 20 male and female volunteer undergraduates at Columbus College who were experimentally naive with regard to PA learning.

\section{Apparatus and Materials}

The apparatus consisted of a LaFayette model memory drum. The PA list consisted of six redundant trigram:digit PAs (FPD:1, BJM:4, KSG:5, TWH:6, XNC:7, LZQ:9), and it was formed (a) by randomly combining consonants and checking for comparability of the individual letter frequency values (Underwood \& Schulz, 1960) for first- vs second- vs third-position components, and (b) by checking to insure that each trigram was of low $M$ and low interletter associative strength (Underwood \& Schulz, 1960). The transfer test consisted of an 18-item list of single letters formed from the PA trigrams. The list of single letters was presented on three separate pages. Six test letters were presented on each page but only one letter from a given trigram occurred on each page. The questionnaire consisted of a set of instructions and a set of questions about how each PA item had been learned; it was presented as a single page. Each $\mathrm{S}$ was requested to proceed as follows: "If you know how you learned these syllables would you please explain below?" Each question was of the following format: "How did you learn, 'LZQ 9'?" A single random order was used to present the list of questions.

\section{Procedure}

Each $S$ was seated and instructed to read the typewritten instructions. The PAs were presented by the study-test method at a 2:2 sec rate with an intertrial interval of $4 \mathrm{sec}$. Four random orders of study items and four (different) random orders of test items were used to present the PAs. The criterion of list mastery was two consecutive errorless trials. Immediately following PA learning, each $\mathrm{S}$ was provided a typewritten set of instructions that explained the single-letter transfer tests. They were then given the three-page booklet and instructed to begin. Upon completion of the single-letter tests, each $\mathrm{S}$ was administered a questionnaire dealing with how the redundant-trigram:digit PAs had been learned. No feedback concerning S's performance was 
Table 1

Classification of Ss' Trigram Processing Strategies

\begin{tabular}{|c|c|c|c|c|}
\hline & Category & Stimulus S Reported Using & & An Example Verbal Report \\
\hline 1 & lnknown & S could not state how a pair was learned. & $\mathrm{XNC}-7$ & "I don't know." \\
\hline 2 & $\begin{array}{l}\text { Single Letter } \\
\text { cues }\end{array}$ & $\begin{array}{l}\text { S reported using a single letter from a tri- } \\
\text { gram (sometimes indicating a positional } \\
\text { basis for selection. sometimes not.) }\end{array}$ & $\mathrm{BJM}-4$ & "Associated the last letter with the number $4 . "$ \\
\hline 3 & Initials & $\begin{array}{l}\text { S selected single or multiple letters that } \\
\text { stood for names of persons, places, or } \\
\text { things (sometimes indicating that he was } \\
\text { using initials. sometimes not.) }\end{array}$ & KSG-5 & "These are my cousins initials-just remember $5 . "$ \\
\hline 4 & $\begin{array}{l}\text { Logical } \\
\text { Relationship }\end{array}$ & $\begin{array}{l}\text { S reported finding some sort of relation- } \\
\text { ship between one or more stimulus } \\
\text { elements and the response. }\end{array}$ & XNC-7 & "X has a slant line as 7." \\
\hline 5 & Coding & $\begin{array}{l}\text { S reported transforming the letters } \\
\text { given into a meaningful word or abbre- } \\
\text { viation. }\end{array}$ & $\mathrm{XNC}-7$ & "I associated it with zinc." \\
\hline
\end{tabular}

given either during the transfer test phase or the questionnaire phase: also, each $\mathrm{S}$ was provided as much time as he wished to complete either phase of the experiment.

\section{RESULTS}

\section{Questionnaire Stage}

All 20 Ss reached the PA learning criterion. Of these, a total of $17 \mathrm{Ss}(85 \%)$ responded to the questionnaire indicating how they had solved at least one of the PA items. One other $\mathrm{S}$ responded to the questionnaire by copying down all the pairs. (The three Ss who did not respond and the $\mathrm{S}$ who rewrote part of the question are ignored in all subsequent analyses.) In all, then, $16 \mathrm{Ss}$ gave some information about how they had learned the six-item PA lists $(16 \times 6=96$ items total). All total, these Ss provided information about how they had learned 72 of the pairs ( $75 \%$ of the items).

Table 1 presents a classification system that was used to organize the Ss' responses. Table 2 shows the frequencies and percentages of each type of verbal report. It can be seen from Table 2 that all of the reports (except five) cound be classified into five categories: (a) strategy was unknown; (b) single letters were selected: (c) initials were selected: (d) logical relationship was perceived between the stimulus term (or part of it) and the response: and (e) stimulus term was coded (transformed) to form something meaningful to the $\mathrm{S}$ (e.g., a word or an abbreviation).

\section{Stimulus Selection Stage}

The questionnaire findings were used in conjunction with the stimulus selection test results in order to examine Berry \& Cole's (1973) notion that a significant amount of redundant-trigram processing is based on initial characteristics. The following procedure was used to determine whether the observed frequency $(\mathrm{N}=19)$ of initial processing (see Table 2) represented a "significant" portion of the items of known processing strategy (i.e.. the single-letter, initials. logical relationship, and coding items of Table 2): (a) first, each
S's transfer test performance was scored for all of the known-processing-strategy items $(\mathrm{N}=72)$; and (b) then each S's transfer performance was rescored, eliminating those items in the initial processing category. In this way, it was possible to contrast stimulus selection test performance with initial items included with such performance with initial items excluded.

A 2 by 3 analysis of variance for two within-Ss variables (Status of Initial Items by Trigram Letter Position) was performed on the number of correct responses achieved to the single letters of the known-processing-strategy PAs. The analysis revealed two significant effects: (a) status of initial items (included vs excluded), $\mathrm{F}(1,15)=\mathrm{p}<.05$; and (b) trigram letter position (first vs second vs third), $F(2,30)=4.0, p<.05$. An analysis of the letter position main effect observed in the known-processing-strategy analysis revealed that the first and third letters accounted for more correct responses than the second letters (both $\mathrm{p}<.01$ ).

Table 2

Frequencies and Percentages (of All Learned PAs, $N=96$ ) of Ss' $(\mathbf{N}=16)$ Reports of How the ConsonantTriad : Digit PAs Were Learned

\begin{tabular}{lcc}
\hline \multicolumn{1}{c}{ Category } & f & $\begin{array}{c}\text { Percent } \\
\text { of Total } \\
\text { Reports }\end{array}$ \\
\hline Unknown* & 19 & 20 \\
Single Letter & 33 & 34 \\
Initials & 19 & 20 \\
Logical Relationship & 11 & 11 \\
Coding & 9 & 9 \\
Total & $91 \div$ & $94 \div$ \\
\hline
\end{tabular}

*Failure to respond was taken as "unknown" providing $S$ gave a description of how he learned at least one pair.

tThese lalues are not exhaustive because of the occurrence of five unintelligible reports (e.g. for FPD-1.S replied "Recog. nition "). 


\section{DISCUSSION}

The present results have shown, among other things, that college Ss do have a tendency to process redundant trigrams on the basis of their initial characteristics. This finding suggests, at least for college Ss, that the redundant-trigram model of PA learning contains a built-in "noise" component that operates to make it more difficult to determine the effects of various parameters on stimulus selection, per se. This is probably especially true when the more analytical measures of stimulus selection, cue selection efficiency and cue selection consistency (Richardson, 1971) are involved. This is not to say that is it impossible to make good use of the redundant-trigram model, but rather it is to say that such application may make for less experimental precision.

Inasmuch as the word-trial model produces much the same results as the redundant-trigram model and, also, inasmuch as the word-triad model is not likely to foster initial processing, it would seem that the word-triad model ought to be preferred to the redundant-trigram model for use in investigations concerned with verbal-element stimulus selection. There are, of course, other reasons for recommending the word-triad over the redundant-trigram paradigm, viz, that the word-triad paradigm imposes no list-length constraints and, more importantly, that it forces attention to stimulus meaning as a basis for stimulus selection. However, the results of the present study are not at all conclusive with respect to determining a choice between the redundant-trigram and word-triad paradigms; instead, they do seem to represent a compelling reason for not employing the redundant-trigram model in parametric investigations of stimulus selection with adult Ss.

\section{REFERENCES}

Baumeister, A. A., \& Berry, F. M. Single-letter cue selection in the paired-associate learning of normal children and retardates. Journal of Experimental Child Psychology, 1970, 9, 400-410.

Berry, F. M., \& Baumeister, A. A. Transfer test methodology in investigations of stimulus selection. Psychological Reports, $1973,32,575-578$.

Berry, F. M., \& Cole, S. R. Stimulus selection in paired-associate learning: Consonant-triad versus word-triad paradigms. Journal of Experimental Psychology, 1973, 97, 402-404.
Berry, F. M., Detterman, D. K., \& Mulhern, T. Stimulus encoding as a function of modality: Aural vs visual paired-associates learning. Journal of Experimental Psychology, 1973, 99, 140-142.

Berry, F. M., Joubert, C. E., \& Baumeister, A. A. Single-letter cue selection and degree of paired-associate learning in retardates. Journal of Experimental Psychology, 1971, 88, 196-204.

Berry, F. M., Joubert, C. E., \& Baumeister, A. A. Single-letter selection in paired-associate learning by retardates as a function of degree of learning. Journal of General Psychology, $1972,87,145-146$.

Davis, W. L., Brown, S. C., \& Ritchie, E. Cue selection as a function of degree of learning and response similarity. Journal of Experimental Psychology, 1968, 78, 323-328.

Horowitz, L. M., Lippman, L. G., Norman, S. A., \& McConkie, G. W. Compound stimuli in paired-associate learning. Journal of Experimental Psychology, 1961, 67, 132-141.

Lovelace, E. A., \& Blass, E. M. Utilizatic n of stimulus elements in paired-associate learning. Journal of Experimental Psychology, 1968, 76, 596-600.

Lovelace, E. A., \& Greenberg, B. Cue selection in paired-associate learning: Length of study interval. American Journal of Psychology, 1969, 82, 254-258.

Postman, L., \& Greenbloom, R. Conditions of cue selection in the a cquisition of paired-associate lists. Journal of Experimental Psychology, 1967, 73, 91-100.

Rabinowitz, F. M., \& McClinton, S. Stimulus selection as a function of letter color and age in paired-associate learning. Developmental Psychology, 1971, 5, 364.

Rabinowitz, F. M., \& Witte, K. L. Stimulus selection as a function of letter color. Journal of Verbal Learning \& Verbal Behavior, 1967, 6, 167-168.

Richardson, J. Cue effectiveness and abstraction in paired-associate learning. Psychological Bulletin, 1971, 75, 73-91.

Richardson, J. Stimulus selection in associative learning. In C. P. Duncan, L. Sechrest, \& A. W. Melton (Eds.), Human memory: Festschrift for Benton J. Underwood. New York: Appleton-Century-Crofts, 1972. Pp. 155-187.

Underwood, B. J., \& Shulz, R. W. Meaningfulness and verbal learning. Philadelphia: Lippincott, 1960.

Wichawut, C., \& Martin, E. Selective stimulus encoding and overlearning in paired-associate learning. Journal of Experimental Psychology, 1970, 85, 383-388.

(Received for publication October 26, 1973.) 